\title{
On the Shoulders of Giants
}

$\mathrm{HMB}$

“W better access to information, better diagnostic tools. Sometimes we are fortunate to meet-and learn from-giants in the profession, whose accumulated wisdom and experience are shared with junior learners. Usually this advice is gleaned with great difficulty; it is not written down or etched in stone. It is a passing remark, a knowing smile, a saying that just sticks in the mind.

There have been many "condors" and "eagles" that have shown me the updrafts of medicine, whose vision has been inspiring, and whose integrity and insight are beacons for those that follow.

I remember the day I told a nurse: "Communication is ninetenths of medicine." She turned quietly, thought for a moment, and said: "Communication is nine-tenths of life." Of course, she was correct. When we hear patients breathing heavily or shuffling hesitantly down the corridor behind us, the dialogue has begun. You turn and hold their cold, frail hands, and a link is forged. You eye their lined visage; their dark, knowing eyes say, "Hear my story." You disarm their anxiety with well-worn pleasantries and seek - through measured inquiry - what it is that brings them to your office. Sometimes you just hit it off, as if you are at some sort of social get-together. Sometimes you have to earn your fee, cutting through a bland defensive visage to a colourful spirit beneath.

I sometimes say: "Well, that's the interrogation over." My new acquaintance sighs and her shoulders relax. A smile creases her face, and she knows things will be okay. The cadence of question and answer is as much a part of medicine as the scalpel is to surgery. A "gatling gun" repartee gives the recipient the impression you are short of time and short of interest. Wait a moment (say "one hundred" to yourself) before moving on, and consider what might to you be a simple answer. When you get good at this job, ask less and learn more. The pregnant pause behind "You don't sleep well; why is that?" may bring out a tearful disclosure, an admission of worrisome facts, or even an accurate self-diagnosis.

I frequently have to remind myself that I am privileged to share in this patient's life story, to be a character in her play or even a chapter in her book. She teaches me my job, since much of learning comes from experience. Her illness may be her burden, but it is my textbook. I tread carefully here, because one day I will be on her side of the desk, worried about a lump, anxious about chest pain, or challenged by arthritis.
Sometimes things don't go well; responses are vague, slow, and poorly formed. I forget that illness dulls the intellect, that age can limit vision and hearing and memory, and that the patient's life experiences may vastly outrank mine. Or I feel hurt by an unexpected challenge, a threat to my integrity. It is a mark of maturity to suppress the rapid pulse, the surging blood pressure, the tunnel vision, and the urge to make a cutting riposte - to stop, to breathe, to "reset," and to salvage a difficult situation.

Every day, I come to work and say to myself: "How many strangers are going to come into my life today? How many friends will leave?" I hope all will have more understanding, more hope, and better health after a consultation. This is what internists can offer: a listening ear, a thoughtful mind, a guiding voice, and above all compassion.

If I had to describe my role in this complex profession, I would liken it to that of a tugboat captain: I seek out ships that are cast adrift, swept close to rocks by unfavourable tides, much like the Russian tanker Simushir, helpless off Western shores for want of a heat pump to put things right. Sometimes all it takes is a strong haul on a sturdy rope, and disaster is averted.

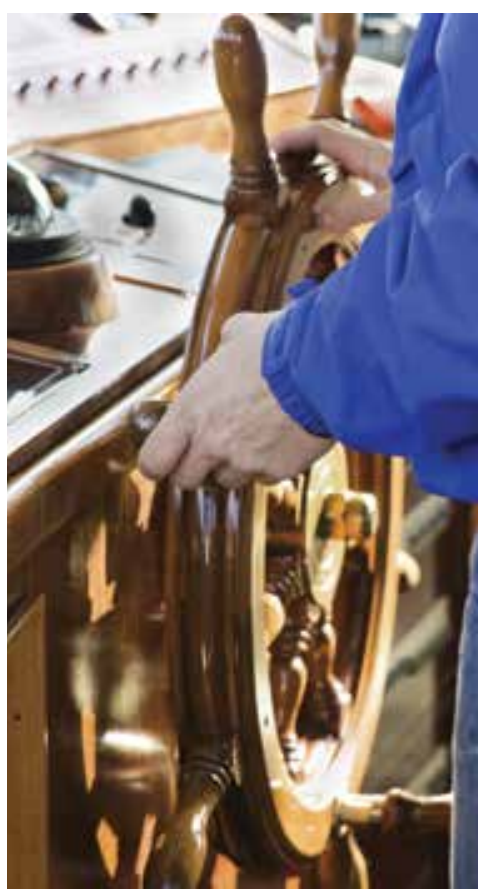
Sometimes, the ship is boarded and the course redrawn, the cargo jettisoned, or the crew removed. If I can't save the vessel and know that the captain will not survive, I have a life jacket and a sailor's prayer. We offer hope and strive to afford a degree of peace and dignity that all of us deserve at the end.

When I started out as a young doctor, I learned the words of Hippocrates: "With purity and holiness I will live my life and practice my art." It has taken me decades of experience to truly understand these words. I hope to have come close to living his values. And I hope that those who follow will bring more to the profession than they take away. 